\title{
Oculomotor nerve palsy related to COVID-19. A case report
}

\section{Parálisis oculomotora relacionada con COVID-19. Reporte de caso}

\author{
Belén Sánchez-Cañal*, Rocío A. Ortiz-Guevara, Lilia Gil-Fernández, Mauricio Cedillo-Ley and \\ Gerardo García-Guzmán \\ Hospital Dr. Sánchez Bulnes, Asociación para Evitar la Ceguera, IAP, Mexico City. Mexico
}

\begin{abstract}
Objective: To report a case of a patient infected with severe acute respiratory syndrome coronavirus-2 (SARS-CoV-2) associated with oculomotor paresis of the sixth cranial nerve. Case report: A 49-year-old patient reported a 2-month history of horizontal diplopia. In addition to diplopia, the patient had mild respiratory symptoms with positivity to SARS-CoV-2. Ocular examination revealed an esotropia of 20 prism diopters, as well as a limitation of the abduction of the left eye of -1.5. The patient was diagnosed with the left sixth nerve palsy that required treatment with botulinum toxin type $A$.
\end{abstract}

Key words: COVID-19. Ophthalmoparesis. SARS-CoV-2. Neuropathy. Oculomotor nerve palsy.

\section{Resumen}

Objetivo: Presentar un caso de un paciente infectado con síndrome respiratorio agudo coronavirus 2 (SARS-CoV-2) al que se asoció una paresia oculomotora del sexto nervio craneal. Caso clínico: Paciente de 49 años de edad que consulta por diplopía horizontal desde hace 2 meses. Asociada a su visión doble presentó un cuadro respiratorio leve con positividad a SARS-CoV-2. La exploración oftalmológica reveló la presencia de endotropía de 20 dioptrías prismáticas, así como limitación de abducción del ojo izquierdo de -1.5. Se le diagnosticó de paresia del sexto nervio craneal izquierdo, la cual requirió tratamiento mediante la aplicación de toxina botulínica tipo $A$.

Palabras clave: COVID-19. Oftalmoparesia. SARS-CoV-2. Neuropatía. Parálisis oculomotora.

\section{Introduction}

Since December 2019, humanity has had to deal with the emergence of an acute and serious disease due to the respiratory coronavirus (COVID-19), a pathology caused by the strain of coronavirus known as severe acute respiratory syndrome coronavirus 2 (SARS-CoV-2) 1 .
Coronavirus disease is not new; coronaviruses have been well known since the 1960s. There are three coronaviruses that can affect humans: the human coronavirus 229E (HCoV-229E), the human coronavirus OC43 ( $\mathrm{HCoV}-\mathrm{OC} 43)$, and, finally, the severe acute respiratory syndrome (SARS)-associated coronavirus. All of them are enveloped viruses with a long-chain RNA genome'.

Correspondence:

*Belén Sánchez-Cañal

Vicente García Torres, 46

Col. San Lucas, Del. Coyoacán

Date of reception: 05-08-2020

Date of acceptance: $23-09-2020$

E-mail: belen.sanchezcanal@gmail.com
Available online: 11-01-2021 Rev Mex Oftalmol (Eng). 2021;95(1):33-36 www.rmo.com.mx 2604-1731/C 2020 Sociedad Mexicana de Oftalmología. Published by Permanyer. This is an open access article under the CC BY-NC-ND license (http://creativecommons.org/licenses/by-nc-nd/4.0/). 
The sites of infection are likely related to the presence of a glycoprotein, dipeptidyl 4, which has a human receptor in the lower respiratory tract, known as angiotensin-converting enzyme 2 (ACE-2). Both SARS-CoV and MERS-CoV (Middle East respiratory syndrome coronavirus) have this surface glycoprotein ${ }^{1}$.

It is known that SARS-CoV-2 can be transmitted by direct or indirect contact with the mucous membranes of the eyes, mouth, or nose, so the respiratory tract should not be considered the only route of transmission. There are recent studies in which they even associate the enteric symptoms of COVID-19, such as nausea and vomiting, due to the presence of invasive enterocytes that express ACE- $2^{1}$.

The clinical manifestations vary from being asymptomatic to symptoms such as fever, cough, diarrhea, and fatigue, and in some cases, the infection leads to severe pneumonia, acute respiratory distress syndrome, and/or death ${ }^{2}$. At present, clinical evidence shows that coronavirus infections are not limited to the respiratory tract, and the existence of associated neurological and ophthalmological manifestations has been reported.

The $1^{\text {st }}$ time conjunctivitis was associated with a human coronavirus was in 2004, in a 7-month-old child, later another case was reported in 2005. However, it is not until this new 2019-2020 outbreak that conjunctivitis has once again been associated with a coronavirus outbreak, this being a sign of COVID-192 infection.

There are reports that provide an overview of the neuro-ophthalmological manifestations reported in patients diagnosed with COVID-193.

\section{Clinical case}

A 49-year-old woman informs a 3-day history of fever, asthenia, myalgia, and headache. On the $4^{\text {th }}$ day, she began with diplopia, blurred vision, and photophobia, persistent dry cough and mild respiratory distress, for which she requested and received medical attention, and began outpatient treatment based on antipyretics, anti-inflammatories, and antibiotics. In that same consultation, a polymerase chain reaction (PCR) test for SARS-CoV-2 was requested, with a positive result. Likewise, a brain MRI was performed during the acute clinical presentation, with normal results.

On admission to the strabismus department, 2 months after the onset of respiratory symptoms, the patient continued with horizontal diplopia. She denied chronic degenerative diseases, as well as associated metabolic diseases. Blood chemistry and hematic biometry were performed at her referral hospital, with all values within

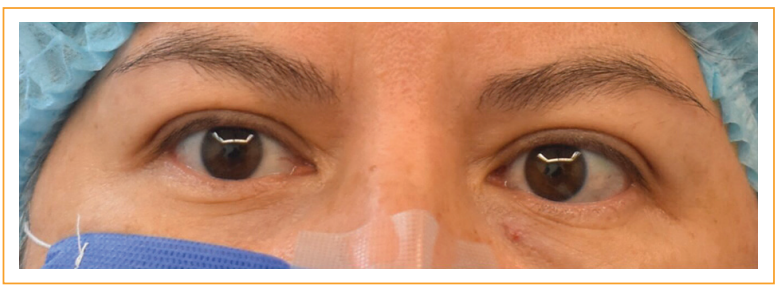

Figure 1. Patient in primary position of gaze with an esotropia of 20 prismatic diopters.

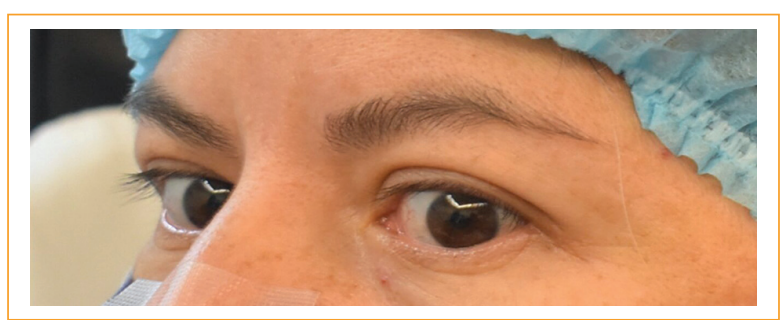

Figure 2. Patient in the left lateral gaze, where the limitation of abduction of the left eye is evident.

normal limits. On ocular examination in the primary gaze position, she had an esotropia of 20 prismatic diopters, with a limitation of abduction of the left eye of -1.5 , the rest of the extraocular muscles were normal (Figs. 1-3). Horizontal diplopia was confirmed with Worth points. The rest of the examination of the anterior pole and the posterior pole of both eyes was normal. Brain MRI was reported within normal limits (Fig. 4). Her best-corrected visual acuity was $20 / 20$ in both eyes. Automatic refraction was performed (right eye -0.75 and left eye -1 ) and later cycloplegic refraction, with similar results.

The patient was questioned about the continuous use of electronic devices which she denied (nevertheless, in this entity, there are no limitations in ductions or asymmetries).

At that time, a left sixth cranial nerve paresis was diagnosed, which required treatment with 8 units of botulinum toxin type $A$ in the left medial rectus muscle. Two weeks after injection, the patient was asymptomatic and orthotropic in primary gaze, without limitation of abduction of the left eye (Fig. 5).

\section{Discussion}

The case of a patient who developed a cranial neuropathy concomitantly with the respiratory symptoms of SARS-CoV-2 infection has been described. 


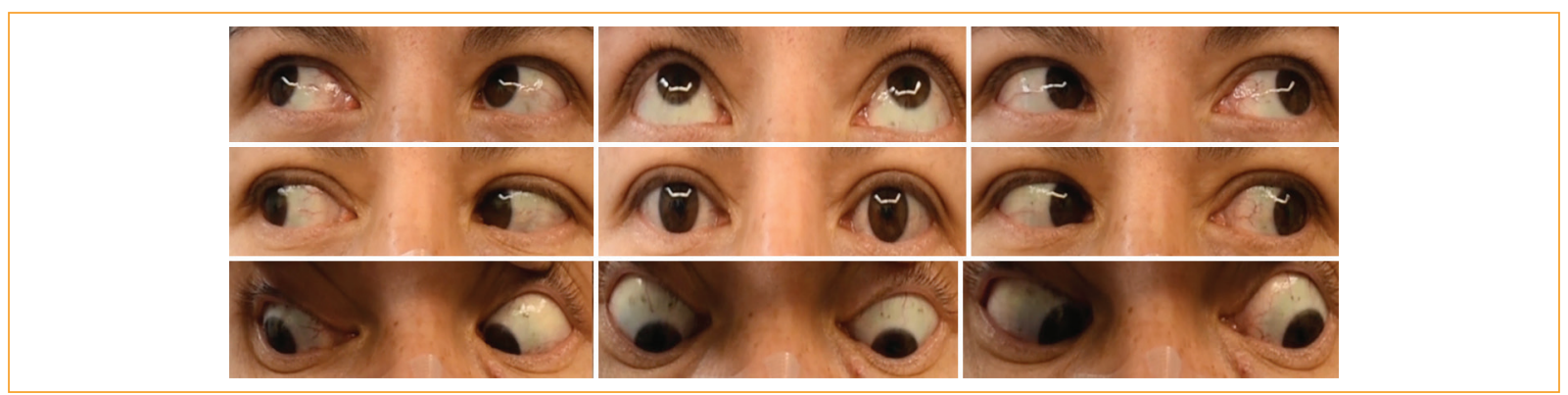

Figure 3. Pictures of the patient in the nine positions of gaze.

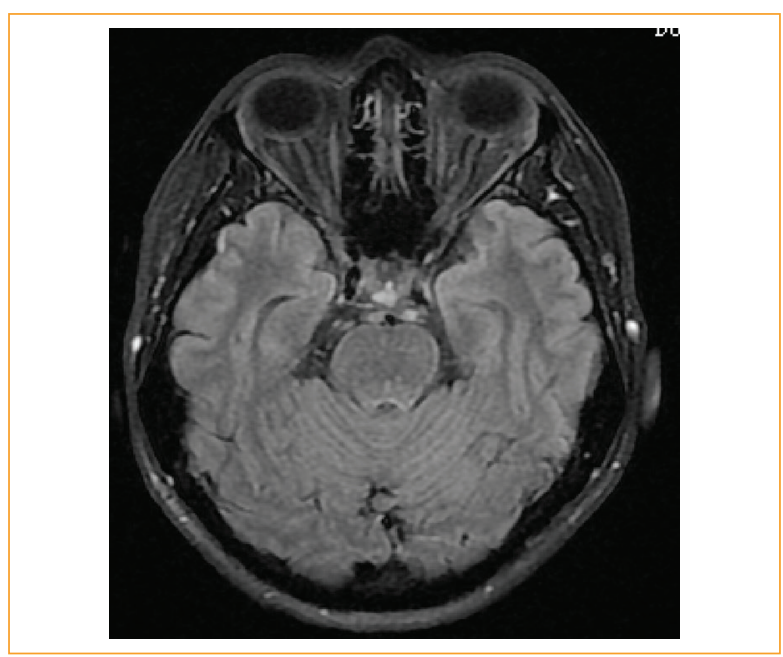

Figure 4. Brain magnetic resonance imaging showing the enhancement at the level of the optic nerves.

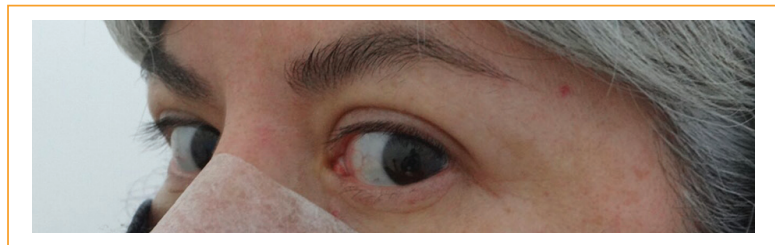

Figure 5. Patient in the left lateral gaze, showing no limitation of movements.

It is believed that the entry of the virus into the central nervous system may be due to the presence of the ACE2 receptor, which, in addition to being expressed in the lungs, heart, vascular endothelium, and kidneys ${ }^{4}$, is expressed in many of the structures of the human brain, such as neurons, microglia, astrocytes, or oligodendrocytes, but also in the nuclei of the base and the motor cortex ${ }^{5}$, making this cell a potential target for SARS-CoV-2. The previous studies revealed that coronaviruses are capable of causing neuronal death in mice by invading the brain through the olfactory pathway ${ }^{6}$.

The affinity of the new coronavirus for these ACE-2 receptors is what explains the multiple neurological manifestations observed in patients with disease due to SARS-CoV-2. In a retrospective study conducted in China that included 214 patients positive for SARS-CoV-2, 36.4\% had neurological complications. Although most were nonspecific symptoms such as headache and dizziness, there were up to $5.7 \%$ cerebrovascular events reported. Hypogeusia and anosmia were also reported, suggesting the involvement of the olfactory bulb, which has been one of the proposed entry mechanisms to the central nervous system?

SARS-CoV-2 is believed to be capable of invading the terminal peripheral nerves (olfactory nerve) and spreading in a retrograde way through nerve synapses to the central nervous system.

It is also possible that the virus crosses the bloodbrain barrier through a mechanism of infection of vascular endothelial cells that express the ACE-2 receptor. Once the virus has access to neuronal and vascular tissue, it will begin its reproduction cycle, progressively inducing more damage to neurons and glial cells.

SARS-CoV-2 is also believed to be capable of infecting white blood cells that cross the blood-brain barrier, thereby infecting the central nervous system. Finally, inflammation created by the virus itself increases the permeability of the blood-brain barrier, which favors the arrival of infected cells ${ }^{8}$ to the central nervous system.

There are also reports of paresis associated with coronavirus infections, after ruling out the most common causes. In adults, the most frequent etiology in our environment is microvascular (due to diabetes mellitus, atherosclerosis, or hypertension); second, due to traumatic causes, and third, tumors 9 .

The exact mechanism of cranial nerve involvement is still unclear. Neurological manifestations can be 
considered as a direct effect of the presence of the virus in the central nervous system or parainfections or immune-mediated post-infections, as can occur in cases in which the SARS-CoV-2 infection manifests itself in the form of a Guillain-Barré syndrome or Miller-Fisher syndrome ${ }^{10}$.

Associated inflammatory factors or even direct damage to myelin fibers have also been reported to cause cranial nerve damage ${ }^{3,11}$.

\section{Conclusions}

SARS-CoV-2 is a new and emerging virus. There are few reports of SARS-CoV-2-associated oculomotor paralysis; however, in these times of pandemic, we must consider SARS-CoV-2 a possible cause of ophthalmological neuropathies.

\section{Ethical disclosures}

Protection of human and animal subjects. The authors declare that no experiments were performed on humans or animals for this study.

Confidentiality of data. The authors declare that they have followed the protocols of their work center on the publication of patient data.

Right to privacy and informed consent. The authors have obtained the written informed consent of the patients or subjects mentioned in the article. The corresponding author is in possession of this document.

\section{Conflicts of interest}

The authors declare no conflicts of interest.

\section{References}

1. Amesty MA, Alió del Barrio J. and Alió J. COVID-19 Disease and Ophthalmology: An Update. Ophthalmol Ther. 2020;9(3):1-12.

2. Von Oertzen TJ. COVID-19 - neurologists stay aware! Eur J Neurol. 2020 May 27; 10.1111/ene.14365.

3. Dinkin M, Gao V, Kahan J, Bobker S, Simonetto M, Wechsler P, et al. COVID-19 presenting with ophthalmoparesis from cranial nerve palsy. Neurology. 2020;95(9):411

4. Baig AM, Khaleeq A, Ali U, Syeda H. Evidence of the COVID-19 Virus Targeting the CNS: Tissue Distribution, Host-Virus Interaction, and Proposed Neurotropic Mechanisms. ACS Chemical Neuroscience. 2020;11(7):995-98.

5. Xia $\mathrm{H}$, Lazartigues $\mathrm{E}$. Angiotensin-converting enzyme 2 in the brain: properties and future directions. J Neurochem. 2008;107(6):1482-94.

6. Netland J, Meyerholz DK, Moore S, Cassell M, Perlman S. Severe acute respiratory syndrome coronavirus infection causes neuronal death in the absence of encephalitis in mice transgenic for human ACE2. J Virol. 2008;82(15):7264-75.

7. Mao L, Jin H, Wang M, Hu Y, Chen S, He Q, et al. Neurologic Manifestations of Hospitalized Patients With Coronavirus Disease 2019 in Wuhan, China. JAMA Neurol. 2020;77(6):1-9.

8. Zubair AS, McAlpine LS, Gardin T. Neuropathogenesis and Neurologic Manifestations of the Coronaviruses in the Age of Coronavirus Disease 2019: A Review. JAMA Neurology. 2020;77(8):1-10.

9. Akagi T, Miyamoto K, Kashii S, Yoshimura N. Cause and prognosis of neurologically isolated third, fourth, or sixth cranial nerve dysfunction in cases of oculomotor palsy. Jap J Ophthalmol. 2008;52(1):32-5.

10. Gutiérrez-Ortiz C, Méndez-Guerrero A, Rodrigo-Rey S, et al. Miller Fisher syndrome and polyneuritis cranialis in COVID-19. Neurology. 2020; 95(5):e601-5.

11. Wei H, Yin H, Huang M, Guo Z. The 2019 novel cornoavirus pneumonia with onset of oculomotor nerve palsy: a case study. J Neurol. 2020;267(5):1550-3. 